\title{
Clinical Spectrum and Etiology of Seizures in Children in Age Group of Two Months to Twelve Years: A Cross Sectional Observational Study
}

\author{
Authors \\ Amardip Kaur ${ }^{1}$, Showkat Hussain Tali ${ }^{2}$, Shagufta Yousuf ${ }^{3}$ \\ ${ }^{1,2}$ Assistant Professor Pediatrics, AIMSR Bathinda, and Punjab \\ ${ }^{3}$ Assistant Professor OBG, AIMSR Bathinda Punjab \\ Email:drdeeep@gmail.com \\ Corresponding Author \\ Showkat Hussain Tali \\ Assistant Professor Paediatrics, AIMSR, Bathinda, Punjab \\ Email:drshowkatshifa@gmail.com
}

\begin{abstract}
Background: Not only the incidence, clinical profile and etiology of seizures vary between populations. This knowledge is very useful for health care planning by health care providers.

Method: A total of 110 cases in age group of 2 months to 12 years brought to emergency department with acute convulsions and those patients admitted in paediatric ward and PICU (Paediatrics Intensive Care Unit) who develop acute seizures were included in the study. Relative incidence of clinical seizure types and etiological factors was determined on the basis of clinical examination and laboratory investigations.

Result: Generalised tonic clonic (GTC) seizures were present in $65.4 \%$ of patients while as $61.8 \%$ of patients were having infective pathology (neuro-infections) as the etological factor for occurrence of seizures.

Conclusion: GTC seizures were the most common clinical seizure type while neuroinfections was the most common etiology factor for seizures in our population.
\end{abstract}

\section{Introduction}

A seizure (from the Latin sacire, "to take possession of") is a paroxysmal event due to abnormal excessive or synchronous neuronal activity in the brain. Depending on the distribution of discharges, this abnormal brain activity can have various manifestations, ranging from dramatic convulsive activity to experiential phenomena not readily discernible by an observer. Although a variety of factors influence the incidence and prevalence of seizures, $5-10 \%$ of the population will have at least one seizure, with the highest incidence occurring in early childhood and late adulthood. ${ }^{(1)}$ A seizure is a general term that is usually used to include any one of the several disorders including epilepsy, febrile seizures and possibly single seizures and seizures secondary to metabolic, infectious, or other etiologies (e.g., hypocalcemia, meningitis). ${ }^{(2)}$

The incidence of epilepsy is $\sim 0.3-0.5 \%$ in different populations throughout the world, and the prevalence of epilepsy has been estimated at 5-10 persons per 1000. Epilepsy in resource-poor 
countries is generally higher in the range of 100-190 cases per 100000 , population per $\mathrm{yr}^{(3)}$. Not only the incidence, clinical profile and etiology of seizures vary between populations. This knowledge is very useful for health care planning by health care providers. This study was designed to find out the clinical spectrum and etiology of seizures in socioeconomically deprived selected Indian population

\section{Materials and Methods}

This study was carried out in a tertiary care level Paediatric and Neonatology Department of Rajendra Institute of Medical sciences. Study period was from February 2013 to June 2014. Before commencing the study ethical clearance from hospital ethical committee was obtained. Informed written consent was taken from the parents or guardians of the patients before enrolment. A total of 110 cases in age group of 2 months to 12 years brought to emergency department with acute convulsions and those patients admitted in paediatric ward and PICU (Paediatrics Intensive Care Unit) who develop acute seizures were included in the study. Type of seizure was determined on the basis of clinical criteria. To determine the etiology, apart from history and clinical examination, CSF (cerebrospinal fluid) examination, ultrasonography of cranium, CT brain, MRI brain and EEG were performed as appropriate.

\section{Observations and Results}

Table 1 depicts baseline and other demographic characters, table 2 clinical spectrum of seizures and able 3 etiological diagnosis

Table 1 Baseline and other demographic characters

\begin{tabular}{|l|c|c|}
\hline Attribute & No.(\%age) & No.(\%age) \\
\hline Age (months) & & \\
\hline $2-11$ & Male : 5 (7.6) & Female: $2(4.6)$ \\
\hline $12-59$ & Male: $36(54.5)$ & Female: $18(40.9)$ \\
\hline $60-144$ & Male: $25(37.9)$ & Female: $24(54.5)$ \\
\hline History of Perinatal asphyxia & & \\
\hline & Yes & $105(95.5)$ \\
\hline & No & $5(4.5)$ \\
\hline Developmental delay & & \\
\hline & Yes & $100(90.9)$ \\
\hline Family history of seizures & No & $10(9.1 \mathrm{~S})$ \\
\hline & & \\
\hline & Yes & $11(10)$ \\
\hline & No & $99(90)$ \\
\hline
\end{tabular}

\section{Discussion}

A total of 110 subjects in the age group of 2 months to 12 years were enrolled in our study. Generalized tonic clonic seizures were the most common clinical seizure type $(65.5 \%)$ at presentation (Table 2).

Table 2 Clinical spectrum of seizures

\begin{tabular}{|l|r|r|r|}
\hline Type of seizure & Male & Female & Total \\
\hline $\begin{array}{l}\text { Generalized } \\
\text { Tonic Clonic }\end{array}$ & $35(63.6)$ & $37(67.3)$ & $72(65.4)$ \\
\hline $\begin{array}{l}\text { Generalized } \\
\text { Tonic }\end{array}$ & $15(27.3)$ & $14(25.4)$ & $29(26.4)$ \\
\hline Partial & $5(9.1)$ & $4(7.3)$ & $9(8.2)$ \\
\hline Total & $55(50)$ & $55(50)$ & $110(100)$ \\
\hline
\end{tabular}

Neuroinfections (combined) were the most common etiological factor. Meningoencephalitis was the most common etiological diagnosis among infective causes $(22.7 \%)$ followed by cerebral malaria $(20.9 \%$; table 3).

Table 3 Etiological diagnosis

\begin{tabular}{|l|c|c|}
\hline Diagnosis & No. of cases & percentage \\
\hline Febrile Convulsion & 9 & $(8.2)$ \\
\hline Pyogenic meningitis & 3 & $(2.7)$ \\
\hline Meningoencephalitis & 25 & $(22.7)$ \\
\hline Cerebral malaria & 23 & $(20.9)$ \\
\hline Neurocystis cercosis & 5 & $(4.6)$ \\
\hline Tubercular meningitis & 8 & $(7.3)$ \\
\hline tuberculoma & 4 & $(3.6)$ \\
\hline Cerebral palsy & 6 & $(5.5)$ \\
\hline Unknown etiology & 27 & $(24.5)$ \\
\hline Total & 110 & $(100)$ \\
\hline
\end{tabular}

\section{Age of Distribution}

In the present study majority of the cases were in the age group less than 5 years of age $(55.45 \%)$. In the study conducted by Koul $\mathrm{R}$ et al ${ }^{(4)}$ as many as $42.65 \%$ cases were below 6 years of age. Shakya $\mathrm{KN}$ et al ${ }^{(5)}$ and Shah et al also reported maximum number of cases (about 56\%) in the age of less than $5 \mathrm{yrs}$ ( $56 \%$ and $75 \%$ respectively).

\section{Sex distribution of the cases}

In present study there was male preponderance. Out of 110 cases of convulsion $66(60 \%)$ were male which is comparable to studies by Senanayake et al ${ }^{(6)}(78 \%)$, Usman et al ${ }^{(7)}(58 \%)$ and Koul R et al ${ }^{(8)}$ $(60.5 \%)$. This could be because generally, for any illness males are brought to medical attention more when compared to females because of the male dominant societal pattern. 


\section{Type of convulsion}

Generalised Tonic Clonic Seizures (GTCS) were the most common type of convulsions (65.45\%) followed by Generalized Tonic Seizure (26.37\%). Tinuade Ogunieso et $\mathrm{al}^{88(9)}$, Koul R et al ${ }^{84(4)}$, Shah et al. ${ }^{5(10)}$ and Shakya et al. ${ }^{(5)}$ found that Generalized Tonic Clonic Seizures were the commonest seizures type $(76.9 \%$ and $72.6 \%, 54.8 \%$ and $36 \%$ respectively)

\section{Family history}

Family history is important while evaluating epilepsy patients because many epileptic syndromes have a familial predisposition and some may possibly have an autosomal dominant pattern of inheritance. $^{(11)}$ Our study showed a positive family history in $10 \%$. In studies by Koul $\mathrm{R}$ et al. ${ }^{(4)}$, positive family history of seizures was reported in $8.9 \%$ cases. Risk of epilepsy increases by 3 folds in first degree relatives. In developing countries due to inbreeding customs, the stigmatism of epilepsy prevents those affected from finding marriage partners from healthy families. Such practice actually increases risk of epilepsy in offspring. ${ }^{(12)}$

\section{Birth history}

In the present study only $4.55 \%$ of the cases had significant birth history mainly in the form of birth asphyxia which was comparable in both the drug groups. In the study conducted by Tinuade Ogunieso et al. ${ }^{(9)}$ birth asphyxia was leading etiology for seizures (37.3\%). This may be related to high fatality of HIE II and HIE III patients in our setup.

\section{Developmental History}

Developmental delay should be evaluated in all cases. Mental retardation, global developmental delay is most common neurologic abnormality with seizures. In the present study $9.09 \%$ had significant developmental delay. Apart from cerebral palsy, developmental delay of varying grades may be found with associated conditions like mental retardation or failure to thrive. Similar findings were reported in reported done by Koul R et al. ${ }^{(13)}$ and Blume WT et al. ${ }^{(14)}$

\section{Diagnosis of the cases}

In the present study majority of the cases were due to neuroinfection with infective cause $(25.45 \%)$ were diagnosed as seizure disorder. $22.73 \%$ were diagnosed as meningoencephalitis, $20.91 \%$ were due to Complicated malaria. $8.18 \%$ were due to febrile convulsion, $7.72 \%$ were due to TBM (Tubercular meningitis), $4.55 \%$ were due to Cererabral palsy, $4.55 \%$ were due to neurocysticercosis, $3.63 \%$ were due to tuberculoma, $2.73 \%$ were due to pyogenic meningitis. These results were comparable to the study done by Pratibha Singhi ${ }^{(15)}$.

\section{Conclusion}

The most common clinical seizure type in our setup is Generalised Tonic Clonic Seizures and the most common etiologic factor is neuro-infection in our study population.

Conflict of interests: Nothing to disclose

\section{Bibliography}

1. Lowenstein DH, Braunwald E, Fauci AS, Kasper DL, Hauser SL, Longo DL. Seizures and Epilepsy. In: Harrison's Principles of Internal Medicine. $18^{\text {th }}$ ed. USA: McGraw-Hill, 2012: 3251-69.

2. Kliegman RM, Stanton BF, St.Geme JW, Schor NF, Behrman RE. Nelson Textbook of Pediatrics. $19^{\text {th }}$ ed.: Philadelphia: Elsevier, 2011: 2013-39.

3. Shorvon S, Guerrini R, Cook M, Lhatoo S D. Seizures in Childhood. In: Oxford Textbook of Epilepsy and Epileptic Seizures. Definitions and Epidemiology of Epilepsy; UK: Oxford University Press, 2013: 51-60.

4. Koul R, Razdan S, Motta A. Prevalence and pattern of epilepsy in rural Kashmir, India. Epilepsia 1988; 29(2):116-22.

5. Shakya KN, Shrestha R, Baral MR. Epilepsy in children an epidemiological study at Kathmandu Medical College Teaching hospitals, Kathamundu. Kathamundu University Medical Journal 2003;1(1):14-19 
6. Senanayake N, Roman GC. Epidemiology of epilepsy in developing countries. Bull WHO 1993; 71(2):247-58.

7. Usman S, Chaudhry HR, Asif A, Yousaf A, Jahangir SF, Gul H, et al. Demographic profile of patients with epilepsy in a community clinic. Part II. Pak J Med Sc 2007 Oct-Dec; 23(6):8736.

8. McMullan J, Sasson C Pancioli A, Silbergleit R. Midazolam versus Diazepam for the treatment of Status Epilepticus in children \& young Adults: A Meta-Analysis. Acad Emerg Med 2010; 17(6): P 575-82.

9. Oguntesi T, Ogundeyi M, Olowu A. Pattern of childhood epilepsies in Sagumu, Nigeria. Indian Pediatr 2009; 76 (4):385-9.

10. Deshmukh C T, Shah I. Intramuscular Midazolam versus Intravenous Diazepam for acute Seizures. Indian J Pediatr 2005; 72(8): 667-70.

11. Mohammad M Kati. Approach to epilepsy in children. Indian J Pediatr 1990; 57:297-312.

12. Abou-Khalil B, Krei L, Lazenby B, Haris PA, Haines JL, Hedra P. Family genetic predisposition, Epilepsy location and antecedent febrile seizures. Epilepsia Res 2007 Jan; 73 (10):104-10.

13. Sjovall S, Kanto J, Himberg JJ, Hovi-Viander M, Salo M. CSF penetration and pharmacokinetic of midazolam. Eur J Clin Pharmacology 1983; 25 (2):247-51.

14. Blume WT. Clinical profile of partial seizures beginning at less than $4^{1 / 2}$ of age epilepsia 1989; 30(6):813-9.

15. Singhi P. Infectious causes of seizures and epilepsy in the developing world. Developmental medicine and child neurology 2011, 53:600-9. 